\title{
UM NOVO OLHAR ACERCA DO INSTITUTO DE MEDIAÇÃO EM PROCESSOS PREVIDENCIÁRIOS DE NATUREZA COLETIVA
}

\section{A NEW APPROACH OF THE MEDIATION INSTITUTE IN COLECTIVE PENSION LAWSUITS}

\author{
${ }^{1}$ Artenira da Silva e Silva Sauaia \\ ${ }^{2}$ Gioliano Antunes Damasceno
}

\section{RESUMO}

No atual contexto de crise da jurisdição decorrente da sobrecarga de processos que assola o Judiciário brasileiro, os mecanismos alternativos de solução de conflito, notadamente a mediação, a conciliação e a arbitragem, são apresentados, pelos órgãos de administração da Justiça, como uma das possibilidades de enfrentamento no que tange a referida crise. Todavia, a utilização desses mecanismos na realidade brasileira deve se dar com cautela, contemplando as especificidades de cada seara do Direito. O objetivo desse artigo é demonstrar que, nos processos judiciais previdenciários individuais, o uso da mediação tem uma margem de eficácia ainda bastante restrita, por força dos contornos objetivos e subjetivos dessa espécie de lide e das injunções impostas pelo fator mora processual. No âmbito coletivo e preventivo, no entanto, é possível avaliar, a partir da análise de casos concretos, que o uso do instituto da mediação evidencia grande utilidade como instrumento de resolução estrutural de conflitos.

Palavras-chave: Mediação, Processo previdenciário, Condicionantes objetivas, Condicionantes subjetivas, Demora processual

\begin{abstract}
In the current context of crisis arising the jurisdiction of procedural burdens plaguing the Brazilian judiciary system, alternative mechanisms of conflict resolution, notably conciliation, mediation and arbitration, are presented, by the agencies that administer justice, as the possibility of positively handling the crisis mentioned above. However, the use of these mechanisms within the Brazilian justice system reality should be handled with caution, according to the particularities of each specific Law area. The aim of this article is to demonstrate that, considering individual pension lawsuits, the use of mediation still has a rather narrow margin of efficiency, due to the objective and subjective contours of these kinds of deals as well as the injunctions imposed by the factor of "procedural delay". In the collective and preventive level, however, the use of the Mediation Institute can be very useful as a tool for structural conflict resolution.
\end{abstract}

Keywords: Mediation, Pension law suits, Objective conditioners, Subjective conditioners, Procedural delay

\footnotetext{
${ }^{1}$ Doutora em Saúde Coletiva pela Universidade Federal da Bahia - UFBA, Salvador, Brasil. Professora adjunta e pesquisadora da Universidade Federal do Maranhão - UFMA, São Luís, Maranhão Brasil. E-mail: tutortreinamento@gmail.com

${ }^{2}$ Mestre em Direito e Instituições do Sistema de Justiça pela Universidade Federal do Maranhão - UFMA, São Luís, Maranhão Brasil. Defensor Público Federal com experiência na área de Direito, com ênfase em Direito. Email: tutortreinamento@gmail.com
} 


\section{INTRODUÇÃO}

Nos últimos anos, tem-se observado um movimento expressivo dos órgãos de gestão do Poder Judiciário Brasileiro no sentido de estimular a utilização de métodos alternativos de resolução de litígios, mais precisamente o uso da conciliação, da mediação e da arbitragem.

Essa iniciativa tem raízes no estrangulamento que esse Poder vem vivenciando, decorrente da sobrecarga de processos experimentada, o que compromete a própria qualidade da prestação jurisdicional, com tramitações processuais mais lentas e redução da capacidade do "ser humano juiz" analisar cada caso concreto com a atenção, precisão e expertise esperadas.

Para vislumbre o difícil cenário de ajuizamento crescente de ações junto ao sistema de justiça considere-se que em 2010 o Instituto Brasileiro de Geografia e Estatística (IBGE) realizou pesquisa sobre Justiça e Vitimização por meio do PNAD (Pesquisa Nacional por Amostra de Domicílio) e detectou que, de 12646 pessoas entrevistadas que tiveram situação de conflito no período de referência, 7308 procuraram a Justiça Ordinária para que seus conflitos fossem resolvidos e 1573 acorreram aos Juizados Especiais, ou seja, 70,2\% das pessoas judicializaram o problema que haviam enfrentado (2010). 22 anos antes, em 1988, o IBGE havia realizado pesquisa semelhante também por meio do PNAD, através da qual identificou que apenas $30 \%$ dos indivíduos envolvidos em disputas procuraram a Justiça Estatal (SADEC, 2001, p. 7). Em outras palavras resta evidente que há um aumento crescente de busca pelo Poder Judiciário como alternativa para a resolução de conflitos sociais das mais diferentes ordens.

Esse cenário de crescimento de judicialização de conflitos de fato sinaliza em direção a uma "crise de jurisdição" que exige a adoção de medidas imediatas, de curto, médio e longo prazos, voltadas para a redução da "conflituosidade social judicializada". Daí que os mecanismos de conciliação, mediação e arbitragem, importados de experiências exitosas empreendidas em países desenvolvidos como o Japão, Estados Unidos e França ${ }^{1}$, surgem como uma possibilidade de solução, mas, urge ressaltar, precisam ser implementados na realidade brasileira e em cada seara do Direito cum grano salis, isto é, com parcimônia e temperamento, observando-se a posição de igualdade e liberdade das pessoas imbricadas em

\footnotetext{
${ }^{1}$ Experiências como o Sistema de Arbitramento Compulsório Francês e o da Filadélfia, Estados Unidos; as Cortes de Conciliação Japonesa; e os Centros de Justiça de Vizinhança também dos Estados Unidos ganharam notoriedade mundial a partir da publicaram do Relatório Geral do Projeto de Florença coordenado por Mauro Cappelletti e Brayant Garth, em 1978, cuja tradução no Brasil ocorreu 1988, sob o título de Acesso à Justiça.
} 
cada tipo de controvérsia judicial (seja ela trabalhista, de família, previdenciária, de saúde, consumerista, de violência doméstica contra a mulher, de infância e juventude), reafirmando políticas cautelosas e bem sedimentadas de estímulo ao manejo desses instrumentos sem que se perca de vista a especificidade de conflitos manejados por cada área do direito em particular. A utilização devida dos mesmos poderá trazer ganhos a todos os envolvidos em diferentes tipos de lides processuais, o contrário, no entanto, pode comprometer a legítima entrega da tutela jurisdiconal a quem efetivamente tem direito a ser tutelado ou pode ainda revitimizar o jurisdicionado, revitimizando-o institucionalmente.

Nessa perspectiva, o objetivo desse artigo é demonstrar como o instituto da mediação parece ter uma margem de efetividade restrita nos processos judiciais individuais previdenciários, notadamente por conta dos contornos objetivos e subjetivos dessa espécie de lide, assim como em virtude das injunções exercidas pelo fator "demora processual". As situações de pobreza em que se encontram os autores dessas ações, associadas a outras condicionantes negativas dos mesmos, como incapacidade laboral, o baixo nível de escolaridade, a natureza alimentar das prestações previdenciárias e o tempo de espera pela resposta estatal, restringem significativamente o espectro de deliberação racional e efetivamente livre desses sujeitos, dificultando o exercício da mediação nas audiências conciliatórias objetivando um deslinde justo para as ações demandadas.

No entanto, defende-se uma utilização muito peculiar do referido instituto no campo do Direito Previdenciário. Empreendida uma guinada de olhar, redirecionando o foco da atuação da mediação para o âmbito coletivo e preventivo observa-se que a referida prática pode se mostrar extremamente válida e útil socialmente, permitindo soluções estruturais de conflitos complexos que atingem uma parcela muito sofrida e vulnerável da população de autores das ações referidas. É o que se passa a demonstrar a partir da análise de casos concretos. Senão vejamos.

\section{MEDIÇÃO: TRAÇANDO UM PRESSUPOSTO CONCEITUAL}

Uma pesquisa mais acurada acerca dos conceitos de mediação e conciliação mostra que não existe um consenso absoluto no que se refere a precisar os conceitos em questão. Carrasco assinala, por exemplo, que, em determinados setores do ordenamento jurídico espanhol, a mediação é concebida como um instrumento que outorga ao mediador a capacidade para propor alternativas de solução de conflito (2009, p. 346). Essa prerrogativa propositiva, no entanto, não seria facultada ao conciliador, cuja função se limitaria a facilitar 
o diálogo entre as partes, evidenciando os argumentos relevantes de cada uma delas (Cuevas 2009).

Cuevas (2009) aponta, entretanto, para uma tendência de utilização desses significantes com significados diametralmente opostos, sendo essa a perspectiva que vem predominando no Direito Brasileiro e, por conseguinte, à qual, para fins meramente metodológicos (estabelecimento de pressupostos conceituais), filiar-se-á este trabalho.

Por essa vertente, na conciliação, o terceiro interventor atua como elo entre os contendores, tendo por finalidade levá-los a possíveis entendimentos, através da identificação de problemas e "da apresentação de possíveis soluções para os mesmos”. Ou seja, o conciliador, diferentemente do mediador, em geral interfere no mérito das questões, "sugerindo" caminhos, cuja decisão final, todavia, cabe somente às partes (MAGALHÃES, 2008, p.28). Já o “mediador", segundo Muõnz e García, seria um terceiro sem objetivo de proposição, o qual não poderia, com sua opinião, intervir diretamente na definição dos termos do acordo, sendo sua missão precípua a restauração do diálogo entre os próprios interessados, trazendo à baila aspectos esclarecedores em relação aos conflitos mediados, antes não observados pelas partes (2007, p. 36). A propósito, Camp (2003) assevera que

"a mediação é o processo de comunicação entre partes em conflito com a ajuda de um mediador, que procurará que as pessoas implicadas em uma disputa possam chegar, por elas mesmas, a estabelecer um acordo que permita reconhecer a boa relação e dar por acabado, ou ao menos mitigado o conflito, que atua preventivamente ou de forma a melhorar as relações com os demais (CAMP, 2003, p. 6).”

A mediação seria, então, um processo no qual uma terceira pessoa ajuda os participantes a manejar um conflito, descortinando aspectos deste que antes não estavam sendo percebidos com clareza pelos litigantes. O acordo resolve o problema com uma solução mutuamente aceita e se estrutura de um modo que ajuda a manter a relação entre as partes implicadas (HAYNES, 2000. p. 2). Tem-se na mediação, portanto, um terceiro que não pretende ter poder sobre as partes. "O mediador", possui como mister facilitar a comunicação, identificar os pontos de controvérsia, fazer aflorar os interesses e necessidades 
e orientar os contendores na busca de um acordo mutuamente satisfatório (PIFERRER et al, 1999). A missão do mediador, destarte, é viabilizar o consenso por meio do exercício racional, prudente e equillibrado da argumentação.

\section{OS CONTORNOS OBJETIVOS E SUBJETIVOS DO PROCESSO JUDICIAL PREVIDENCIÁRIO E O ASPECTO TEMPORAL: EMBARAÇOS PARA O EXERCÍCIO EXERCÍCIO DA MEDIAÇÃO}

Segundo Savaris (2010), o processo previdenciário se destaca do processo civil clássico porque apresenta determinadas particularidades de caráter objetivo e subjetivo, relacionadas ao direito material vindicado e às partes envolvidas na lide, que o singulariza.

O direito material em disputa, nesses casos, constitui bem de índole alimentar, considerado um direito humano fundamental, intimamente ligado à dignidade da pessoa humana. Trata-se de prestação pecuniária reservada à satisfação das necessidades mais prementes do cidadão, presumivelmente imprescindível para seu sustento digno, sem destituições indevidas ou privações persistentes (SAVARIS, 2010). Decerto,

"Um bem jurídico previdenciário corresponde à ideia de uma prestação indispensável à manutenção do indivíduo que a persegue em juízo. Essa primeira noção é não só reconhecidamente bastante basilar, mas extremamente importante: uma prestação previdenciária tem natureza alimentar; destina-se a prover recursos de subsistência digna para os beneficiários da previdência social que se encontrem nas contingências sociais definidas em lei: destina-se a suprir as necessidades primárias, vitais e presumivelmente urgentes do segurado e de sua família, tais como alimentação, saúde, higiene, vestuário, transporte, moradia etc. $\mathrm{O}$ que está em jogo em uma ação previdenciária são valores sine qua non para a sobrevivência de modo decente. É o direito de não depender da misericórdia ou auxílio de outrem" (SAVARIS, 2010, p. 58). 
Quanto aos sujeitos imbricados, de um lado, tem-se o segurado, geralmente pessoa de baixa renda que precisa, com máxima urgência, do amparo financeiro pleiteado para garantir sua própria sobrevivência, cercado que se encontra, em tese, de contingência social prevista em lei (idade avançada, incapacidade laboral, gravidez, desemprego involuntário, prisão), sem condições reais de desempenhar uma atividade remunerada. No outro polo da relação jurídico processual, figura o Instituto Nacional de Seguro Social - INSS, autarquia federal, entidade pública responsável pela gestão dos recursos da previdência. Em outras palavras, o Estado, em sentido amplo (SAVARIS, 2010).

Esse cenário de flagrante desigualdade na relação jurídico-processual compromete sensivelmente o exercício dos institutos da mediação e ou da conciliação como alternativa justa de resolução de conflitos nos processos previdenciários.

Nesse âmbito, a procuradoria do INSS, sem pressões de quaisquer ordens, encontra- se numa posição de conforto, sendo-lhe absolutamente indiferente se o pretendente do benefício aceitará ou não a proposta lançada, além de beneficiar-se de um deslinde moroso para o conflito posto. $\mathrm{O}$ aceite de qualquer acordo trar-lhe-á a vantagem financeira representada no quinhão renunciado pela parte contrária; a recusa, por sua vez, no máximo, impor-lhe-á o ônus de recorrer contra eventual sentença procedente condenatória ao pagamento da quantia que já deveria ter sido quitada desde o requerimento administrativo do benefício. Exercer a mediação nesse espaço, buscando o convencimento da Autarquia Previdenciária no sentido de reconhecer integralmente o direito do demandante ou de, pelo menos, aumentar, em geral significativamente, o percentual da proposta apresentada afigura- se um desafio deveras hercúleo, para não dizer quixotesco, embora necessário, inclusive para que o demandante se sinta em exercício de sua cidadania no curso de uma audiência onde se percebe enfrentando o Estado.

No outro vértice, em geral vivendo em situação socioeconômica precária, o autor de uma demanda previdenciária não possui margem razoável de deliberação. Sua liberdade para avaliar qualquer proposta de acordo feita está parcialmente comprometida pela situação de vulnerabilidade na qual frequentemente se encontra. A prática da mediação para tentar convencê-lo a aderir ao acordo exsurge mesmo desnecessária, latente que são os motivos, vivos no cotidiano de penúria, para não recusá-lo, muito embora, não se pode olvidar, seja de extrema valia como instrumento de empoderamento do assistido na sua busca por um acordo mais próximo possível da satisfação integral de seu direito. 
Essa tendência do demandado a abrir mão de parcelas significativas de seus direitos aparece ainda mais forte diante da longa espera experimentada entre a data da entrada do requerimento administrativo (a DER) e o termo de ciência da próstata da avença; sem falar na ameaça de uma demora ainda maior em caso de não aceitação, decorrente da interposição de recurso pelo INSS contra a possível sentença procedente. Com efeito, a "demora e os altos índices de inflação tornam um demandante em busca de um numerário, especialmente quando se trata de um indivíduo isolado, mais ansioso por uma composição, mesmo que injusta, de modo a poder receber alguma quantia desde logo" (CAPPELLETTI; GARTH, 1988, p. 88).

Vê-se, portanto, que essa miscelânea de fatores - caráter alimentar da verba requerida, litigância contra o Estado, pobreza extrema da parte autora, demora processual efetivamente dificulta o exercício da conciliação e até da mediação no micro plano dos processos individuais previdenciários sem que se comprometa um deslinde justo para este tipo de lide.

A seguir, a fim de embasar uma reflexão crítica mais apurada das dificuldades apontadas acima, a partir de pesquisa empírica sobre processos que tramitaram na Defensoria Pública da União no Maranhão, mostrar-se-á como esses elementos influenciam a decisão de aceite dos assistidos dessa Instituição.

\section{CONCILIAÇÕES EM MATÉRIA DE DIREITO PREVIDENCIÁRIO NO ÂMBITO DO JUIZADO ESPECIAL FEDERAL DO MARANHÃO: UMA ANÁLISE DA HIPOSUFICIÊNCIA SÓCIOECONÔMICA DAS PARTES E DO FATOR TEMPO EMBASANDO O ACEITE DE ACORDO (ESTUDO DE CASOS)}

$\mathrm{Na}$ presente pesquisa, foram escolhidas, aleatoriamente, 10 situações levadas à Defensoria Pública da União no Maranhão - DPU/MA, que deram ensejo à instauração de procedimentos de assistência jurídica gratuita (PAJ), os quais tramitaram no $2^{\circ}$ Ofício de Direito Previdenciário, titularizado por um dos autores deste artigo. ${ }^{2}$ Trata-se de procedimentos através dos quais os assistidos buscavam a obtenção de algum benefício

\footnotetext{
${ }^{2}$ Por motivos práticos, não foi possível efetuar o levantamento do total dos acordos firmados no período, vez que tal empresa demandaria uma pesquisa individualizada de cada processo, identificando em quais foram celebrados acordos. A escolha dos casos analisados se deu por critério aleatório e pragmático, ou seja: foram separados aqueles que tinham manifestações de aceite de acordo registradas no banco de petições do $2^{\circ}$ Ofício Previdenciário. Nesse sentido, não entraram na pesquisa aqueles casos em que a aceitação se deu oralmente, em audiência, dispensando o protocolo de petição.
} 
previdenciário ou assistencial (auxílio doença, aposentadoria por invalidez, aposentadoria por idade, pensão por morte e benefício assistencial de prestação continuada à pessoa com deficiência - BPC/LOAS).

Os acordos foram firmados entre julho 2013 e setembro de 2014. A análise foi empreendida sobre as informações registradas nos PAJ's, a partir daquilo que foi declarado pelos assistidos e também dos registros constantes dos documentos anexados - carteiras de trabalho e previdência social - CTPS, petições iniciais e documentos emitidos pelo Instituto Nacional de Seguro Social - INSS. Além disso, foram colhidos dados dos processos judiciais no bojo dos quais os acordos foram entabulados, especialmente das atas de audiências, dos laudos e das petições do INSS com as propostas de acordo.

À exceção de um caso, todos os acordos foram assinados com a assistência jurídica da DPU. Disso, pode-se presumir que existia, pelo menos, do ponto de vista jurídicoinformacional, um certo equilíbrio entre as partes contratantes, na medida em que é praxe dessa Instituição esclarecer o assistido de todas consequências da aceitação e da recusa da proposta apresentada, sendo a decisão final exclusivamente do próprio interessado. ${ }^{3} \mathrm{O}$ único acordo assinado sem a participação da DPU ocorreu no caso 3, no qual a assistida procurou a Instituição já na fase de execução do processo judicial requerendo assistência jurídica para ver cumprida a avença acordada. Tecidas essas considerações sobre o procedimento de coleta dos dados a seguir apresentados, passa-se à análise dos dados sistematizados.

QUADRO 1: Características dos autores das ações

\begin{tabular}{|c|c|c|c|c|c|c|}
\hline & $\begin{array}{l}\text { Renda } \\
\text { familiar } \\
\text { per capita } \\
\text { (em reais) }\end{array}$ & Profissão & Situação laboral & Idade & Escolaridade & $\begin{array}{l}\text { Incapacidade } \\
\text { laboral }\end{array}$ \\
\hline $\begin{array}{l}\text { Caso } \\
1\end{array}$ & 1000 & Carpinteiro & $\begin{array}{l}\text { Afastada por } \\
\text { motivo de saúde }\end{array}$ & 58 & $\begin{array}{l}\text { Médio } \\
\text { completo }\end{array}$ & Sim \\
\hline $\begin{array}{l}\text { Caso } \\
2 \\
\end{array}$ & 0 & Lavrador & $\begin{array}{l}\text { Afastada por } \\
\text { motivo de saúde }\end{array}$ & 50 & $\begin{array}{l}\text { Fundamental } \\
\text { incompleto }\end{array}$ & Sim \\
\hline $\begin{array}{l}\text { Caso } \\
3\end{array}$ & 35 & Lavrador & Desempregada & 55 & Analfabeto & Não \\
\hline $\begin{array}{l}\text { Caso } \\
4\end{array}$ & 64 & Pescador & $\begin{array}{l}\text { Afastada por } \\
\text { motivo de saúde }\end{array}$ & 28 & $\begin{array}{l}\text { Médio } \\
\text { completo }\end{array}$ & Sim \\
\hline $\begin{array}{l}\text { Caso } \\
5\end{array}$ & 127,5 & $\begin{array}{l}\text { Não } \\
\text { informada }\end{array}$ & Desempregado & 48 & $\begin{array}{l}\text { Fundamental } \\
\text { incompleto }\end{array}$ & \\
\hline Caso & 0 & Costureira & Afastada & 53 & Médio & Sim \\
\hline
\end{tabular}

\footnotetext{
${ }^{3}$ Esse diálogo com o assistido possibilita um momento de exercício da mediação no âmbito das audiências de conciliação, em que se busca, por meio da educação jurídica, lançar luzes sobre todos os "prós e contras" da decisão do aceite do acordo, discriminando as vantagens e as desvantagens envolvidas nos acordos propostos, permitindo ao assistido a melhor escolha conforme as peculiaridades do seu contexto de vida.
} 


\begin{tabular}{|l|l|l|l|l|l|l|}
\hline 6 & & & motivo de saúde & & completo & \\
\hline $\begin{array}{l}\text { Caso } \\
7\end{array}$ & 74 & $\begin{array}{l}\text { Não } \\
\text { informada } \\
\text { (Sem registro } \\
\text { na CTPS) }\end{array}$ & $\begin{array}{l}\text { Afastada por } \\
\text { motivo de saúde }\end{array}$ & 56 & $\begin{array}{l}\text { Fundamental } \\
\text { incompleto }\end{array}$ & Sim \\
\hline $\begin{array}{l}\text { Caso } \\
8\end{array}$ & 240 & $\begin{array}{l}\text { Não trabalha } \\
\text { (criança de 1 } \\
\text { ano) }\end{array}$ & $\begin{array}{l}\text { Não trabalha } \\
\text { (criança de 1 } \\
\text { ano) }\end{array}$ & 1 & $\begin{array}{l}\text { Nunca estudou } \\
\text { (criança de 1 1 } \\
\text { ano) }\end{array}$ & $\begin{array}{l}\text { Não trabalha } \\
\text { (criança de 1 } \\
\text { ano) }\end{array}$ \\
\hline $\begin{array}{l}\text { Caso } \\
9\end{array}$ & 375 & $\begin{array}{l}\text { Autônoma - } \\
\text { Economia } \\
\text { informal } \\
\text { (venda de } \\
\text { lanche em } \\
\text { quiosque) }\end{array}$ & $\begin{array}{l}\text { Afastada por } \\
\text { motivo de saúde }\end{array}$ & 56 & $\begin{array}{l}\text { Fundamental } \\
\text { completo }\end{array}$ & Sim \\
\hline $\begin{array}{l}\text { Caso } \\
10\end{array}$ & 155 & $\begin{array}{l}\text { Empregada } \\
\text { doméstica }\end{array}$ & $\begin{array}{l}\text { Afastada por } \\
\text { motivo de saúde }\end{array}$ & 56 & $\begin{array}{l}\text { Fundamental } \\
\text { incompleto }\end{array}$ & Sim \\
\hline
\end{tabular}

Do quadro 1, extrai-se que a maioria das pessoas envolvidas no estudo: 1) pertencem a famílias de baixa renda, assim consideradas aquelas cuja renda familiar per capita é igual ou inferior a $1 / 2$ do salário mínimo ou aquela que possua renda absoluta mensal de até três salários mínimos, nos termos do artigo 4", inciso II, alíneas "a" e "b", do Decreto da Presidência da República $6135 / 2007^{45}$; 2) tem histórico profissional de atividades braçais; 3) estavam em situação de incapacidade laboral por motivo de saúde; 4) possuem um nível de escolaridade que oscila entre o nível fundamental e o nível médio ${ }^{6}$.

A baixa renda das famílias avaliadas denota um contexto de privação quanto ao atendimento adequado de necessidades basilares para o ser humano, como alimentação,

\footnotetext{
${ }^{4}$ Art. $4^{\mathrm{o}}$ Para fins deste Decreto, adotam-se as seguintes definições:

(...)

II - família de baixa renda: sem prejuízo do disposto no inciso I:
}

a) aquela com renda familiar mensal per capita de até meio salário mínimo; ou

b) a que possua renda familiar mensal de até três salários mínimos;

${ }^{5}$ A baixa renda da grande maioria das pessoas que judicializam demandas previdenciárias é confirmada com dados do Instituto Brasileiro de Geografia e Estatística - IBGE, por meio de pesquisa realizada em 2009, que apontou que $31,3 \%$ dos entrevistados que buscavam o Judiciário para resolver questões relacionadas a benefícios do INSS ou previdência tinham renda familiar absoluta de superior a 1 e inferior a 2 salários mínimos, ao passo que $23,7 \%$ tinham renda entre $1 / 2$ e 1 salário mínimo. Apenas $16 \%$ tinham renda igual ou superior a 2 salários mínimos (2010).

${ }^{6} \mathrm{O}$ baixo grau de escolaridade das pessoas que judicializam demandas previdenciárias também pode ser confirmado com dados do Instituto Brasileiro de Geografia e Estatística - IBGE, por meio de pesquisa realizada em 2009, que apontou que $49,1 \%$ dos entrevistados tinham apenas o ensino fundamental incompleto; $20,7 \%$ não tinham qualquer instrução; e somente 5,2\% tinham o nível superior completo (2010). 
medicamentos, tratamento de saúde, vestuário e transporte. Por outro lado, em todos os casos, os assistidos não tinham, antes do acordo, uma fonte de renda formal fixa, de modo que o benefício então vindicado tinha justamente a finalidade de lhes garantir uma subsistência de forma independente, sem precisar da ajuda ou misericórdia de familiares ou ainda da caridade alheia.

Essa circunstância está ligada, na maioria dos casos, ao quadro de incapacidade laboral, que impedia o sujeito de trabalhar na sua profissão habitual enquanto aguardava o curso do processo judicial. Como se não bastasse, o contexto se agravava com a interferência dos outros fatores, como o aumento da idade, o nível de escolaridade baixa ou mediana e o histórico profissional eminentemente braçal, condições que lhe dificultavam o reingresso no mercado de trabalho por meio de outra profissão que não a habitual, mas compatível com a sua limitação clínica vivenciada.

No caso 2, por exemplo, tem-se um assistido com 50 anos de idade, sem fonte de renda familiar, detentor apenas do nível fundamental incompleto, lavrador durante toda a vida (cortador de cana), mas inapto fisicamente para continuar trabalhando como tal (com quadro de cegueira do olho direito e visão subnormal no olho esquerdo - CID10 54.1), não estava habilitado para laborar em outro ramo profissional, de sorte que aguardou todo o processo sofrendo dificuldades de toda ordem, até o momento em que lhe foi apresentada a proposta, quase irrecusável, de acordo.

Em síntese, em virtude do estado de pobreza e vulnerabilidade experimentado, essas pessoas precisavam urgentemente de uma fonte de recursos que lhes assegurasse o mínimo existencial e, voltadas para essa perspectiva, não vislumbravam alternativa senão a obtenção do benefício pleiteado, vez que não tinham condições de trabalhar. Seria, então, quase impossível exigir-lhes conduta diversa da aceitação do acordo aventado pelo INSS. São jurisdicionados que possuem sua liberdade de transacionar limitadas por contingências adversas de vida das mais variadas ordens.

QUADRO 2: Tempo de espera entre a data de entrada do requerimento administrativo (DER) ou a data de cessação do benefício (DCB) e a data de aceite do acordo.

\begin{tabular}{|l|l|l|l|}
\hline & DER/DCB & Data do aceite & Tempo de espera \\
\hline Caso 1 & $23 / 03 / 2011$ & $\begin{array}{l}2 \text { anos, } 4 \text { meses e 2 } \\
\text { dias (854 dias) }\end{array}$ \\
\hline
\end{tabular}




\begin{tabular}{|l|l|l|l|}
\hline Caso 2 & $02 / 03 / 2011$ & $11 / 07 / 2013$ & $\begin{array}{l}2 \text { anos, } 4 \text { meses e 11 } \\
\text { dias (863 dias) }\end{array}$ \\
\hline Caso 3 & $17 / 11 / 2011$ & $19 / 08 / 2013$ & $\begin{array}{l}1 \text { ano, 9 meses e 3 } \\
\text { dias (642 dias) }\end{array}$ \\
\hline Caso 4 & $15 / 10 / 2012$ & $\begin{array}{l}1 \text { ano, 2 meses e 23 } \\
\text { dias (450 dias) }\end{array}$ \\
\hline Caso 5 & $25 / 03 / 2010$ & $08 / 01 / 2014$ & $\begin{array}{l}3 \text { anos, 9 meses e 17 } \\
\text { dias (1386 dias) }\end{array}$ \\
\hline Caso 6 & $29 / 11 / 2012$ & $13 / 05 / 2014$ & $\begin{array}{l}1 \text { ano, } 5 \text { meses e 13 } \\
\text { dias (531 dias) }\end{array}$ \\
\hline Caso 7 & $26 / 04 / 2012$ & $15 / 05 / 2014$ & $\begin{array}{l}2 \text { anos e } 19 \text { dias (750 } \\
\text { dias) }\end{array}$ \\
\hline Caso 8 & $28 / 02 / 2013$ & $05 / 09 / 2014$ & $\begin{array}{l}1 \text { ano, 6 meses e 7 } \\
\text { dias (555 dias) }\end{array}$ \\
\hline Caso 9 & $25 / 09 / 2013$ & $09 / 09 / 2014$ & $\begin{array}{l}11 \text { meses e 15 dias } \\
(350 \text { dias) }\end{array}$ \\
\hline Caso 10 & $04 / 01 / 2012$ & $\begin{array}{l}2 \text { anos e } 8 \text { meses } \\
(974 \text { dias) }\end{array}$ \\
\hline
\end{tabular}

Através do Quadro 2, observa-se que o tempo de espera do assistido entre a data em que formalizou seu requerimento administrativo perante o INSS ou a data em que teve seu benefício cessado e o momento em que aceita a proposta da Autarquia Seguradora é relativamente longo. O cidadão que menos aguardou foi o do caso 9 , chegando seu tempo de espera a 11 meses e 15 dias.

No caso 8, cuidava-se de uma criança de 1 ano e 5 meses de idade que buscava o BPC/LOAS. Apresentava, conforme informações extraídas do laudo médico emitido em seu processo judicial, a seguinte história clínica: síndrome de down, com dispinéia desde o nascimento, lipotomia cardiopatia, compatível com diagnóstico citogenético de trissomia livre do cromossomo 21, em tratamento na PROCAPE - Universidade de Pernambuco, aguardando avaliação para cirurgia cardíaca, devido alteração na hipotensão e hipersistência vascular pulmonar. O infante tinha, no momento da perícia, tosse produtiva com secreção, cianose perioral e de extremidade e dificuldade de ganho de peso. Segundo o perito, o diagnóstico etiológico ou sindrômico mais provável era de síndrome de Down (CID Q90.0) e má formação congênita dos septos cardíacos (CID Q21.0), sendo o prognóstico, mesmo com tratamento, considerado ruim. $\mathrm{O}$ assistente social que atuou no processo como perito, por seu turno, emitiu laudo registrando que o assistido morava com o pai, a mãe, o irmão e uma prima, sendo que a única renda da casa provinha de seu pai, que trabalhava como servidor público e recebia remuneração na ordem de $\mathrm{R} \$ 1200,00$, ou seja, a renda familiar per capita, 
como mostra o Quadro 1, era de R \$240,00. Relata ainda que a família possuía despesas mensais em torno de $\mathrm{R} \$ 719,00$ para a compra de medicamentos para a criança, os quais não eram dispensados gratuitamente pelos órgãos do Sistema Único de Saúde.

Diante de todo esse quadro, depois de uma espera de 1 ano, 6 meses e 7 dias, perguntase se de fato havia como os pais da criança recusarem a proposta de acordo do INSS, abrindo mão de parcela dos valores que eram devidos ao filho, mesmo depois de todo o sofrimento vivido desde a DER do BPC/LAOS. A demora processual parece funcionar, em diversas áreas do direito,como fator coercitivo de renúncia de direitos que deveria ser concebidos pelo Estado como indisponíveis, porquanto umbilicalmente ligados à dignidade de seus titulares. Ou se diz "sim", ou o sujeito, ainda que vitorioso na ação, é condenado a uma espera ainda maior em função da quase certa interposição de recurso pelo INSS contra a sentença procedente, procrastinando ad eternum o recebimento das prestações (alimentares) não quitadas e por vezes inclusive definindo literalmente uma sentença de morte do demandante da ação.

Quadro 3: Percentuais dos valores dos acordos firmados em comparação com os valores devidos.

\begin{tabular}{|l|l|l|}
\hline & Maior ou igual a 80\% & Igual ou menor que 60\% \\
\hline Caso 1 & & $\mathrm{x}$ \\
\hline Caso 2 & & $\mathrm{x}$ \\
\hline Caso 3 & & $\mathrm{x}$ \\
\hline Caso 4 & $\mathrm{x}$ & \\
\hline Caso 5 & & $\mathrm{x}$ \\
\hline Caso 6 & $\mathrm{x}$ & \\
\hline Caso 7 & $\mathrm{x}$ & \\
\hline Caso 8 & $\mathrm{x}$ & \\
\hline Caso 9 & $\mathrm{x}$ & \\
\hline Caso 10 & & $\mathrm{x}$ \\
\hline
\end{tabular}

Pelo quadro 3, vê-se que, em metade dos casos, a perda financeira do autor da ação não superou $20 \%$. Nessas situações, pode-se dizer que o percentual relativamente menor da renúncia contribuiu decisivamente para o aceite, na medida em que o acordo foi considerado, contextualmente, bom. Todavia, os assistidos também firmaram a avença mesmo nos casos em que a proposta não passou de $60 \%$ do valor devido, possivelmente por conta da demora na resposta estatal ao atendimento de sua demanda e das circunstâncias pessoais desfavoráveis 
nas quais estavam imbricadas, como precariedade socioeconômica, o baixo nível de escolaridade, o estado de incapacidade laboral e o próprio desgaste experimentado pelos jurisdicionados ao judicializarem um conflito. No caso 10, por exemplo, a assistida, uma empregada doméstica de baixa renda e incapacitada para o trabalho, que já aguardava 2 anos e 8 meses pelo amparo assistencial, aceitou uma proposta de acordo para passar a perceber o BPC/LOAS e receber R $\$ 11.200,00$ como ressarcimento pelas parcelas não quitadas. No entanto, se não aceitasse, receberia algo em torno de $\mathrm{R} \$ 21.700,00$, ou seja, a avença foi fixada em patamar aproximado a 50\% da cifra efetivamente devida, o que constitui prejuízo expressivo para uma pessoa que sobrevive em situação de pobreza.

A partir dos casos pesquisados, confirma-se a ideia de que as adversidades vividas e o estado de necessidade e vulnerabilidade experimentado pela grande maioria dos cidadãos que acorrem ao Judiciário para obter algum benefício previdenciário ou assistencial encontram-se em situação de absoluta desvantagem no que tange à manifestação de sua real vontade na "mesa negociação", sendo temerário sustentar a generalização do exercício razoável da conciliação nesse âmbito. Essa prática na seara previdenciária requer a superação das dificuldades apontadas, permitido a construção de um ambiente em que sujeitos livres e iguais tenham condições materiais de barganhar efetivamente por seus interesses de modo equilibrado. Nessa perspectiva, a atuação coletiva e preventiva da DPU sinaliza para uma possibilidade de deslinde mais justo para estas lides .

\section{A ATUAÇÃo dA DPU E A MEDIAÇÃo COMO PRÁticA COLETIVA E PREVENTIVA: POSSIBILIDADES NO ÂMBITO PREVIDENCIÁRIO}

Tem-se sustentado até aqui que o quadro de privação extrema vivenciado pelos segurados que acionam o aparelho judicial em busca de benefícios previdenciários e assistências, associado ao fator tempo e ao desgaste por eles experimentado no curso de uma marcha processual, compromete de forma aguda a capacidade dos mesmos para deliberar racionalmente acerca da composição dos conflitos que vivenciam. Assim, para tornar possível o exercício da mediação nesse campo, compreendida com prática de convencimento argumentativo das partes a aceitarem uma solução consensual justa, é preciso encontrar formas de afastar ou de minimizar cada um desses fatores de impedimento. 
Nesse senda, trazer o debate para o campo inter-institucional, retirando o conflito do contexto "indivíduo versus Estado", parece ser uma possibilidade de efetivação de justiça no âmbito previdenciário. Nesse aspecto, o fomento da atuação coletiva e preventiva da DPU em matéria previdenciária apresenta pontos positivos, na medida em que a Instituição, autônoma que é, não sofre as injunções socioeconômicas típicas dos casos individuais, além do que possibilita a adoção de medidas corretivas antes dos conflitos se instaurarem ou se agravarem, isto é, previamente à consumação ou ao agravamento do sofrimento humano decorrente da supressão do direito, deixando fora da pauta qualquer discussão relacionada à influência do fator tempo.

À guisa de exemplificação do que ora está sendo sugerido, em 2011, a partir de demandas individuais que chegavam à DPU/MA, identificou-se que havia uma espera demasiada e generalizada dos segurados entre a data do agendamento de seus atendimentos nas Agências de Previdência Social do Maranhão e o dia do efetivo atendimento. No plano individual, as questões levadas ao órgão foram ajuizadas como de praxe, diante da inércia da Administração Previdenciária em dar uma resposta aos assistidos em tempo hábil ou considerado razoável. No entanto, paralelamente, foi instaurado, no Ofício de Direitos Humanos e Tutela Coletiva do Maranhão, procedimento de assistência jurídica com a finalidade de tentar resolver preventivamente o problema, de modo que se pudesse evitar a reiteração de ações individuais com a mesma causa de pedir.

Nesse procedimento coletivo, foram realizadas várias tratativas entre a DPU e o INSS, onde se efetuou exposições das consequências do problema tanto sobre as esferas jurídicas dos assistidos bem como também para o próprio funcionamento das Instituições do Sistema de Justiça, já que a demora no atendimento repercutia no surgimento de demandas individuais, quer em forma de ofícios enviados ao INSS requerendo maior celeridade administrativa no trato das ações, quer em novas ações judiciais interpostas. De seu turno, nos espaços de discussão, a Autarquia Previdenciária explicitou também como uma das razões para a ineficiência do serviço, a existência de fraudes no serviço de agendamento, com esquemas de reservas fictícias de vagas para posterior venda, o que congestionava a fila de espera. 
Após intensa mediação por parte da DPU ${ }^{7}$, houve a compreensão do INSS de que, de fato, era preciso aperfeiçoar os procedimentos institucionais internos, dando mais celeridade à tramitação processual. Assim, conseguiu-se fazer com que o Tempo Médio de Espera de Atendimento (TMEA) sofresse redução de 57\%, reduzindo-se a período menor que 45 dias. Os resultados foram obtidos por meio de um plano de ação implementado pela Gerência Executiva do INSS de São Luís, com o acompanhamento da Superintendência Regional de Recife.

Esse caso demonstra significativa utilidade da mediação no âmbito coletivo em matéria previdenciária. Com efeito, havia um conflito instaurado entre a coletividade de segurados que faziam uso dos serviços previdenciários e a própria Autarquia. A DPU, intervindo como mediadora, colocando em destaque os embaraços causados pela demora processual, convenceu a Administração Pública de que era preciso tomar providências para solucionar o imbróglio, e assim foi feito. Em momento algum houve qualquer tipo de injunção externa sobre a autonomia de atuação da DPU, seja de ordem socioeconômica, seja de natureza temporal. A problemática foi abordada racionalmente, e o consenso foi obtido a partir da evidenciação de que a solução encontrada era efetivamente a mais satisfatória e não menos importante, a mais justa.

\section{CONSIDERAÇÕES FINAIS}

A mediação pode ser compreendida como um processo informal de resolução de conflitos, em que um terceiro, sem o poder de decisão, assiste às partes com a finalidade de otimizar a comunicação entre elas e de alcançar um consenso em direção a um deslinde justo de uma ação. O mediador, sem decidir e sem entregar uma proposta pronta de acerto, auxilia os contendores a, racionalmente, acordarem uma solução, visibilizando aspectos do conflito não percebidos ou não considerados pelas partes antes de uma atuação mediadora.

\footnotetext{
${ }^{7}$ Importante esclarecer que, nesse caso, houve o ajuizamento de uma Ação Civil Pública pela DPU, requerendo que o INSS adequasse seus procedimentos de agendamento à garantia de razoável duração processual, todavia o processo foi suspenso antes da análise do provimento de urgência por pedido da própria DPU, após a sinalização do INSS de que havia aperfeiçoado seu sistema de marcação de atendimento.
} 
O processo previdenciário é marcado por um objeto de natureza eminentemente alimentar e por partes em condições completamente desiguais na relação jurídico processual: de um lado, o segurado em situação de vulnerabilidade social precisando do amparo urgente da Previdência; de outro, o Estado, personificado na figura do INSS. Esse contexto, associado à demora processual, compromete sensivelmente a livre manifestação de vontade dos autores nas audiências de conciliação realizadas nos processos individuais previdenciários, tornando difícil o exercício da mediação.

Decerto, a mediação, nessa área previdenciária, requer a superação ou minimização das barreiras socioeconômicas que impedem os sujeitos de barganharem, com igualdade e com liberdade, por seus interesses. Nessa perspectiva, a atuação coletiva e preventiva da DPU sinaliza para uma possibilidade justa de resolução de conflitos, na medida em que viabiliza o debate inter-institucional, retirando o conflito do contexto "indivíduo versus Estado". Assim, afastam-se as interferências socioeconômicas e de caráter temporal (demora processual) da "mesa de negociação", garantindo que o debate se preserve no plano da racionalidade e da razoabilidade e da garantia de direitos.

Contudo, é importante asseverar que as conciliações nos processos previdenciários não podem simplesmente ser extintas, mas precisam ser repensadas cuidadosamente. Com efeito, o problema da sobrecarga de processos está na agenda dos órgãos de cúpula do Judiciário, e a conciliação, como instrumento redutor da carga laboral dos juízes, mostra-se como uma alternativa para a minimização da aludida sobrecarga. Todavia, não se pode descuidar do seu caráter em geral paliativo, porquanto por vezes lesivo ao patrimônio do segurado, e necessariamente complementar, cuja implementação deve ser acompanhada de ações de abrangência coletiva e preventiva de conflitos individuais, dimensão onde a mediação exerce papel fundamental.

\section{REFERÊNCIAS}

CAPPELLETTI, Mauro; GARTH, Bryant. Acesso à justiça. Porto Alegre: Fabris, 1988.

CAMP, Eduard Vinyamata. Aprender mediación. Ediciones Paidós Ibérica, S, A, 2003 
CARRASCO, M. Blanco. Mediación y sistemas alternativos de resolución de conflictos. Madrid: Editora Reus, 2009.

CUEVAS, Joaquín Cayón de las. Resolución extrajudicial de conflictos sanitarios: manifestaciones jurídico-positivas y posibilidades de futuro. 2009.

HAYNES, John. Fundamentos de la mediación familiar. España: editorial Gaia, 2000.

MAGALHÃES, Rodrigo Almeida. Formas alternativas de resolução de conflitos. Belo Horizonte: RHJ, 2008.

MINISTÉRIO DA ECONOMIA, FAZENDA E PLANEJAMENTO. Fundação Instituto Brasileiro de Geografia e Estatística. Características da vitimização e do acesso à justiça no Brasil. Pesquisa Nacional por Amostra de Domicílios 2009 - Suplemento. Disponível em: http://www.ibge.gov.br/home/estatistica/populacao/vitimizacao_acesso_justica_2009/default. $\underline{\text { shtm. }}$. 